\title{
Repetition causes confusion: Insights to word segmentation during Chinese reading
}

Jingwen Wang ${ }^{1,2}$ Bernhard Angele ${ }^{3,4}$ Guojie $\mathrm{Ma}^{5} \quad$ Xingshan $\mathrm{Li}^{1}$

1. CAS Key Laboratory of Behavioral Science, Institute of Psychology, Beijing, China

2. Department of Psychology, University of Chinese Academy of Sciences, Beijing, China

3. Department of Psychology, Faculty of Science and Technology, Bournemouth University, Poole, UK

4. Centro de Ciencia Cognitiva (C3), Universidad Nebrija, Madrid, Spain

5. Shaanxi Key Laboratory of Behavior and Cognitive Neuroscience, School of Psychology, Shaanxi Normal University

Author Note

This research was supported by grants from the National Natural Science Foundation of China (31970992, 31571125)). This work was also jointly funded by the National Natural Science Foundation of China (NSFC) and the German Research Foundation (DFG) in Project Crossmodal Learning, NSFC 61621136008/DFG TRR169. Dr. Bernhard Angele was supported by the CAS President's International Fellowship Initiative by Chinese Academy of Sciences.

Correspondence should be addressed to Xingshan Li, 16 Lincui Road, Key Laboratory of Behavioral Science, Institute of Psychology, Chinese Academy of Sciences, Beijing, China. Email: lixs@psych.ac.cn, or to Guojie Ma, Email: magj@snnu.edu.cn. 


\begin{abstract}
Since there are no spaces between words to mark word boundaries in Chinese, it is common to see two identical neighboring characters in natural text. Usually, this occurs when there are two adjacent words containing the same character (we will call such a coincidental sequence of two identical characters repeated characters). In the present study, we examined how Chinese readers process words when there are repeated characters. In three experiments, we compared how Chinese readers process four-character strings including two repeated characters (e.g. 行动动机, pinyin: xíngdòng dòngjīi, meaning behavioral motivation) with a control condition where none of the characters repeat (e.g.行动欲望, pinyin: xíngdòng yùwàng, meaning behavioural desire). In Experiment 1, the four-character strings were presented for $40 \mathrm{~ms}$ and participants were asked to report as many characters as possible. Participants reported the second and third characters less accurately in the repeated condition than the control condition. In Experiments $2 \mathrm{~A}$ and 2B, we embedded two different types of four-character strings, compound Chinese characters and simple Chinese characters, into the same sentence frames, and asked participants to read these sentences normally. Gaze duration and total time on the second word were significantly longer in the repeated condition. These results suggest that the repeated characters increased the difficulty of word processing. Moreover, the results are consistent with the predictions of serial models which assumes that words are processed serially in reading.
\end{abstract}

Keywords: Chinese reading, word segmentation, eye movements, repeated characters 


\section{Repetition causes confusion: Insights to word segmentation during Chinese reading}

The part of the visual field from which readers can efficiently obtain information is known as the perceptual span. In Chinese reading, this span usually extends one character to the left and three characters to the right of fixation (Inhoff \& Liu, 1998). Given that most words in Chinese have a length of two characters, but one- and threecharacter words are also quite common, the five characters which fall inside the perceptual span during each fixation can constitute one word, two words, or more words. Occasionally, it will also include fragments of words, with the rest of the word outside the span. How characters and words in the perceptual span are processed has been the subject of much scientific interest in English reading (Rayner, 2009; Schotter, Angele, \& Rayner, 2012). Arguably, this phenomenon is even more interesting when considering reading in Chinese. In an alphabetical language, inter-word spaces are important cues to mark word boundaries, so readers can segment words by using lowlevel visual cues (Rayner, 1998). Unlike in alphabetical languages, there are no spaces between words in written Chinese text. However, words still play an important role in Chinese reading (Li, Gu, Liu, \& Rayner, 2013). Thus, how characters are grouped into words (word segmentation) and how words and characters within the perceptual span influence each other during processing is an important question that is still under investigation.

In alphabetic language, two kinds of models explain how readers process words during reading. One of them assumes that words are processed serially (e.g., E-Z Reader 
model; Reichle, Pollatsek, Fisher, \& Rayner,1998). According to this model, words are processed one by one from left to right during reading. The processing of a word does not start until the previous one has been completely accessed. Thus, while the properties of a former word can influence the processing of the latter ones, the reverse does not work. The other kind of models assume that words in the perceptual span are processed in parallel at any given time (e.g., SWIFT model; Engbert, Nuthmann, Richter, \& Kliegl, 2005). According to this model, all of the words in the perceptual span influence each other during processing. Although both kinds of models can explain how alphabetic words are processed during reading, how Chinese words are processed is still under investigation. In the present study, we use repeated characters to investigate whether Chinese word in the perceptual span during reading are processed in serial or parallel.

The repeated characters refer to the two identical adjacent characters that belong to two different words in text. For example, in the character strings 行动动机 (pronounced as xingdòng dòngjī in Chinese pinyin, means behavioral motivation), the characters 动 are repeated characters. Since most Chinese characters can constitute many different words, this happens quite often in Chinese reading (around 0.329\%) (Zhan, Guo, \& Chen, 2003).

Previous studies using three different paradigms have shown that people usually have difficulty perceiving either successively or simultaneously presented identical letters and words. The first line of findings demonstrating this was called the repeatedletter inferiority effect (Bjork \& Murray, 1977; Egeth \& Santee, 1981; Santee \& Egeth, 1980). In these studies, multiple characters are usually shown briefly and followed by 
a mask, and participants were asked to report the character at a cued position. The accuracy of report was lower when the target letter was identical to its neighbour than when it was different. The second line of findings was called the homogeneity effect (Frick, 1987; Mozer, 1989). In those studies, when asked to count the number of digits (or letters) in the display, people usually made more mistakes when counting the number of characters in a string of identical digits (or letters) than when counting different digits (or letters) (Frick, 1987; Mozer, 1989). The third line of findings was called repetition blindness effect (Kanwisher,1987). In those studies, people had difficulties in reporting the repeated items which were successively or simultaneously presented in rapid serial visual paradigm. Although using different paradigms, these three lines of research suggest that humans have difficulty perceiving pairs or multiples of identical letters or words when they are shown briefly.

Many theories have been proposed to account for the difficulty of perceiving repeated items (Crowder, 1968; Gilinsky, 1968; Kanwisher,1987; Masson, 2004; Park \& Kanwisher,1994; Potter, 1984; Rachel \& Sally, 2008; Whittlesea, Dorken, \& Podrouzek, 1995). One influential theory suggests that the inhibition effect of processing repeated items could be explained by the token individuation hypothesis (Kanwisher, 1987; Kanwisher, 1990; Kanwisher \& Potter, 1991). To successfully perceive objects, people need to distinguish the object's type and token. Type refers to the abstract representation of the object and token refers to the representation of the exact object with the temporal and spatial information. People first recognize type and then token. The process of characterizing one particular object as a token is called token 
individuation. However, when two tokens of the same type are shown briefly, the second token is much more difficult to individuate than the first (Kanwisher,1990).

In the studies that showed repetition inhibition effects, the repeated letters or words are usually shown in isolation and are usually shown very briefly. When the repeated words were embedded in the sentences during natural reading, there was evidence that repeated words facilitate the processing of the first word. One study using a natural reading task found that a neighbouring repeated word could facilitate the processing of current fixated word (mother's was fixated for less time when it was followed by mother than when it was followed by father). Of course, even though the constructions used are grammatical, they are still highly unusual (there are very few situations in which native speakers would use mother's mother rather than grandmother or even maternal grandmother) (Inhoff, Radach, Starr, \& Greenberg, 2000). Angele, Tran and Rayner (2013) used the gaze-contingent boundary paradigm (Rayner, 1975) to present the repeated word as a temporary parafoveal preview to the right of the currently fixated word. For example, in the sentence "He read the news this morning" the preview of "this" while participants fixated on "news" could be either the actual subsequent word ("this", correct preview control condition), a repetition of the currently fixated word "news", an orthographically similar nonword neighbor of that word ("niws"), a semantically related word ("tale") or a dissimilar control preview ("rzmc"). Once readers' eyes crossed the boundary located between "news" and "this", the preview changed to the actual post-boundary word ("this"), thereby avoiding the need for unusual grammatical constructions. Angele et al. found a facilitation effect on fixation 
duration on the pre-boundary word "news" in both the repetition preview condition (news) and the orthographically related nonword preview condition (niws), but not in the semantically related preview condition. As these results suggest that facilitation might happen at orthographic level, it is reasonable to assume that repeated characters in Chinese might also facilitate word processing.

Although these findings from English suggest that, under some circumstances, repeated information in the parafovea can facilitate fovea processing. It is important to note that, in English, word or morpheme repetitions are rather uncommon and do not sound very natural (e.g. "the baby's sitter" sounds more natural than "the baby's babysitter" and "the classroom key" sounds more natural than "the classroom room key"). However, in Chinese, it is not unusual or unnatural at all to see one word ending in the same character that the next one begins with. In the present study, we investigated how repeated characters influence word processing during Chinese reading using a whole report task (in Experiment 1) and a natural reading task (in Experiments $2 \mathrm{~A}$ and $2 \mathrm{~B}$ ), which can shed some light on the debate regarding to what degree words are processed serially or in parallel during reading (Radach \& Kennedy, 2013). If Chinese words are processed serially, once the first word containing one of the repeated characters is identified, the processing of the word containing another repeated character will be more difficult according to the token individuation hypothesis, as once one of the repeated characters is individuated, the second repeated character is less likely to be individuated. Therefore, the second word which contains the second repeated character will need more time to process. During natural Chinese reading, 
readers read from left to right so that the words on the left are usually processed earlier than words on the right. Thus, serial models predict that the left word containing the repeated characters should not be affected much during natural reading. However, the processing of the right word that containing the repeated character should be prolonged since the repeated character has difficulty being tokenized. On the other hand, if Chinese words are processed in parallel, the repeated characters should also be processed at the same time, avoiding the token individuation problem and possibly even facilitating processing as suggested by Angele et al.'s (2013) results.

In Experiment 1, we used a whole report task, presenting a four-character string briefly in each trial and asked participants to report as many characters as possible. This allows us to investigate the recognition of repeated characters in the context of word reading using a task similar to those that have been used in previous studies on repetition blindness in simultaneously presented stimuli (Kanwisher, 1990). We compared the report accuracies at four positions in the repeated condition with those in the control condition. If the repeated characters are processed serially, their report accuracy in the repeated condition should be lower. On the other hand, if the repeated characters are processed in parallel, the report accuracy of both repeated characters should be similar to (or even higher than) the accuracy in the control condition.

With Experiment 2, we aimed to investigate the processing of repeated characters in a natural reading task. In Experiments $2 \mathrm{~A}$ and $2 \mathrm{~B}$, participants read sentences in which either a repeated four-character string or a four-character string without repeated characters was embedded. By using this method, we investigated how people process 
the words containing repeated characters in a natural way. Participants' eye movements were tracked while they read these sentences naturally. Eye tracking is a useful method to investigate how individuals process repeated letters or words in normal reading, since participants can just read the sentences at their own pace while their eye movements are being recorded.

In Experiment 2A, the repeated characters were compound characters, which are characters that are constituted by more than one radical (a radical is a separable component of a character). For example, the character 她 (tā, meaning she), is constituted by the two radicals 女 and 也, with the radical 女 (nü, meaning woman), providing semantic information. The critical four-character strings used in Experiment 2A were exactly the same as those used in Experiment 1 in order to compare the effect of repeated characters on processing of isolated characters and on word processing in sentence reading.

In Experiment 2B, we used simple characters as the critical characters in order to examine whether the effect observed with complex characters can be extended to simple characters. The repeated compound characters are constituted by more than one radical, and thus the repeated radicals are never directly adjacent. For example, in the string 行动动机, although the two characters in the middle are identical (动动), the radicals (力 and 云) are never repeated directly adjacent to each other. On the other hand, for simple characters, both the repeated characters and the repeated radicals are directly adjacent (e.g., 稻田田鼠, dàotián tiánshŭ, meaning field mouse in the field). Experiment 2 was designed to investigate whether repetition at both radical level and 
character level would cause stronger repetition effects.

In both Experiments $2 \mathrm{~A}$ and $2 \mathrm{~B}$, we hypothesize that if words containing repeated characters are processed serially, reading times on the word containing the second repeated character should be longer than that in the control condition without repetition but reading time on the first word should be similar in both conditions. However, if words contain repeated characters are processed in parallel, we may observe equal influence on both words in reading time and the reading time is likely to be shorter in the repeated condition than the control condition.

\section{Experiment 1}

\section{Method}

Participants. Thirty-six native Chinese speakers (age: $M=21.94, S D=2.46 ; 13$ males) from universities near the Institute of Psychology, Chinese Academy of Sciences, took part in the experiment. They received a small monetary compensation for their participation. All participants had either normal or corrected to normal vision, and were naïve regarding the purpose of the experiment. The study was approved by the ethics committee of the Institute of Psychology, Chinese Academy of Sciences.

Materials. Sixty pairs of four-character strings (ABCD) were used in Experiment 1. The first two characters $\mathrm{AB}$ constituted a word, and the last two characters $\mathrm{CD}$ constituted another word. However, ABCD was never a word. Each pair of strings shared the same two-character word $\mathrm{AB}$ (e.g., 行动 for both the repeated condition 行 动动机 and the control condition 行动欲望). In the repeated condition, the second 
character and the third character were identical (e.g., 行动动机, xíngdòng dòngjī, meaning behavioural motivation). In the control condition, the second and third characters were different (e.g., 行动欲望, xíngdòng yùwàng, meaning behavioural desire). Within each pair of strings, the word frequency of word $\mathrm{CD}$, the character frequency and stroke numbers of character $\mathrm{C}$ and $\mathrm{D}$ were matched between the repeated condition and the control condition (all $p \mathrm{~s}>.1$; see Table 1). Each participant saw half of the strings in the repeated condition and the other half in the control condition. Thirty filler strings were added such that each participant read ninety experimental trials, which were presented in a random order following eight practice trials.

\section{Table 1}

\section{Properties of materials used in Experiment 1}

\begin{tabular}{|c|c|c|c|c|}
\hline & \multicolumn{2}{|c|}{ First word $(\mathrm{AB})$} & \multicolumn{2}{|c|}{ Second word (CD) } \\
\hline & Repeated & Control & Repeated & Control \\
\hline Word frequency & $49(84)$ & $49(70)$ & $43(71)$ & $42(77)$ \\
\hline $\begin{array}{c}\text { Character frequency of the first } \\
\text { character }\end{array}$ & $1138(1072)$ & $1138(1072)$ & 969 (1101) & $844(1025)$ \\
\hline $\begin{array}{c}\text { Character frequency of the } \\
\text { second character }\end{array}$ & $969(1101)$ & $969(1101)$ & $1300(1682)$ & $1376(1612)$ \\
\hline $\begin{array}{c}\text { Stroke number of the first } \\
\text { character }\end{array}$ & $7.87(2.95)$ & $7.87(2.95)$ & $9.07(2.79)$ & $8.57(2.59)$ \\
\hline $\begin{array}{l}\text { Stroke number of the second } \\
\text { character }\end{array}$ & $9.07(2.79)$ & $9.07(2.79)$ & $7.07(2.78)$ & $7.70(2.79)$ \\
\hline
\end{tabular}

Notes: 1) SDs are given in parentheses. 2) The units of word frequency and character frequency was times of occurrence per million. 3) In both the repeated and the control condition the first word $\mathrm{AB}$ are exactly the same (e.g. 行动 of both 行动动机 in the repeated condition and 行动欲望 in the control condition). 4) The first character refers to $\mathrm{A}$ in the first word and $\mathrm{C}$ in the second word. The second character refers to $\mathrm{B}$ in the first word and D in the second word.

Apparatus. The materials were presented on a 21-inch CRT monitor (Sony 
Multiscan G520) with a $1,024 \times 768$ pixel resolution and a refresh rate of $150 \mathrm{~Hz}$. The character strings were shown in 24-point Song font in black (RGB: 0, 0, 0) on a white background (RGB: 256, 256, 256). The participants' eyes were approximately $58 \mathrm{~cm}$ away from the computer monitor. At this viewing distance, each character subtended a visual angle of about $1.2^{\circ}$. Eye movements were monitored by an Eyelink 1000 eye tracking system (SR Research, Mississauga, Ontario, Canada) with a sampling rate of 1,000 Hz. The participants placed their chins on a chin-rest and leaned their foreheads against a forehead rest to minimize head movements.

Procedure. The eye tracker was calibrated at the beginning of the experiment and was calibrated again as needed. A five-point calibration procedure was used. The maximal error of the validation was $0.5^{\circ}$ in visual angle. When participants successfully fixated on a cross located at the center of the screen, a four-character string was presented for $40 \mathrm{~ms}$. The first character was always presented at the position occupied by the fixation cross. Since the presentation duration was very short, the eye tracker was used to ensure that participants always fixated the first character during each trial. By doing so, the participants could view the four characters as they would in natural reading, which is from left to right (Li, Rayner, \& Cave, 2009). A black and grey mosaic mask (see Figure 1) then appeared until the next trial started. Participants were encouraged to report as many characters as possible orally with no time limitation. They were instructed to report a character as "*”" if they perceived something at a position, but could not identify that character. The experimenter recorded the participants' responses by inputting the results into the experimental computer after each trial. Each 
character reported by the participant was inputted in the order as he/she reported. After the experimenter recorded the participant's response, she pressed a key on the keyboard to start the next trial.

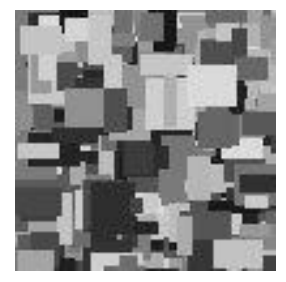

Figure 1. An example of the masks used in Experiment 1.

\section{Results}

In order to examine the influence of repeated characters, we analyzed the accuracy in the repeated and control conditions at all of the four positions separately using generalized linear mixed models (Baayen, Davidson, \& Bates, 2008). As we performed two-tailed tests at the 5\% alpha level, the critical values for the Wald test statistic were -1.96 and 1.96. 


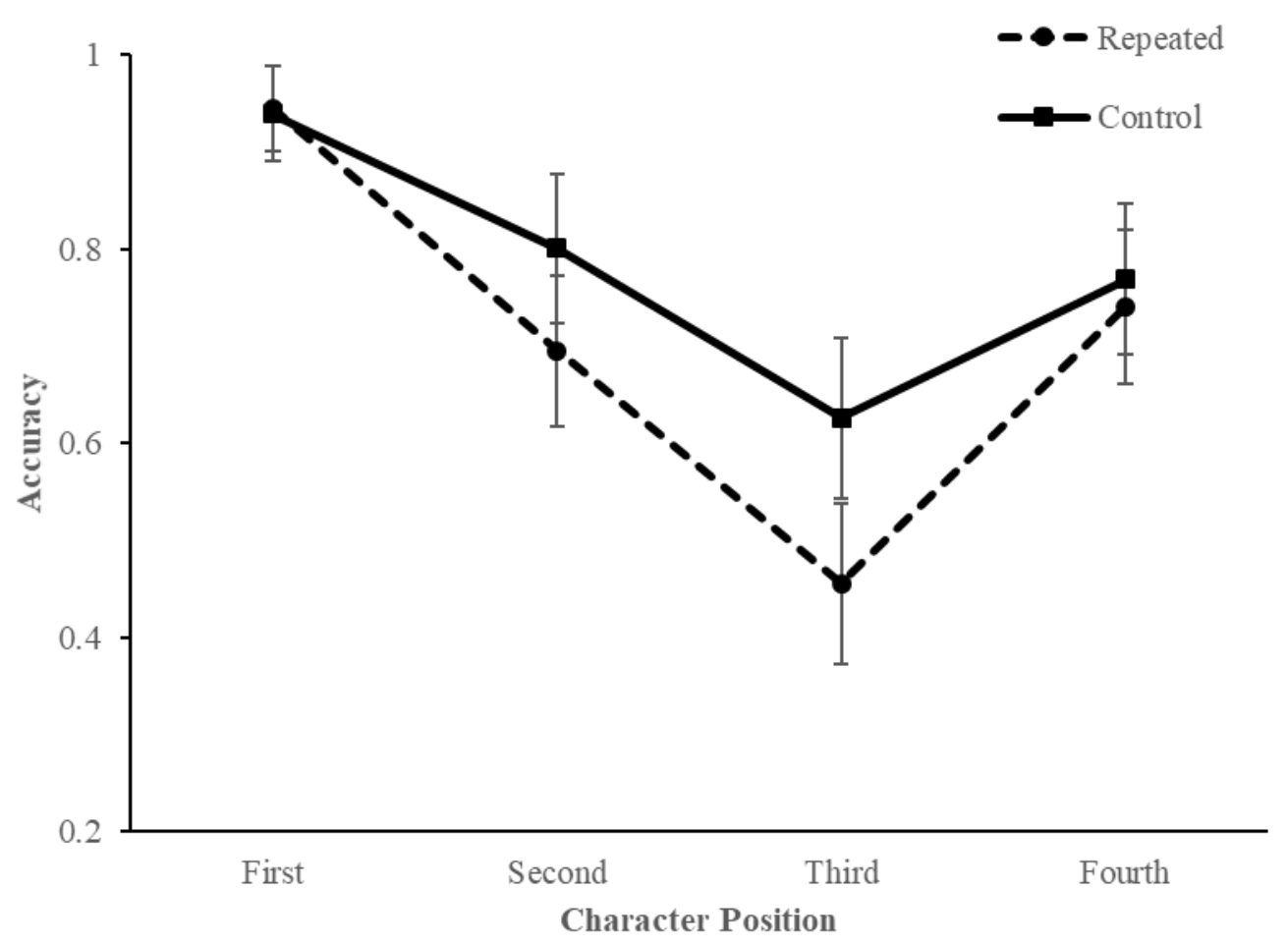

Figure 2. Accuracy of character recognition at four positions in two conditions in Experiment 1. Error bars represent standard errors.

As shown in Figure 2, the recognition accuracies for the second and third characters in the repeated condition were significantly lower than those in the control condition $(b$ $=-0.75, S E=0.14, z=-5.36, p<.001 ; b=-0.89, S E=0.13, z=-6.85, p<.001$ respectively). None of the other comparisons indicated a significant difference between the two conditions ( $p s>.1)$. 


\section{Table 2.}

The distributions of character report accuracy for the second and third characters in Experiment 1.

\begin{tabular}{ccc}
\hline & Control & Repeated \\
\hline Both characters correct & .49 & .23 \\
Only second character correct & .22 & .44 \\
Only third character correct & .08 & .21 \\
No character correct & .18 & .11 \\
\hline
\end{tabular}

As shown in Table 2, participants were less likely to report both characters correctly in the repeated condition (23\%) than in the control condition (49\%). In the repeated conditions, participants could usually only report one of the repeated characters. They only reported the second character correctly in $44 \%$ of trials, and only reported the third character correctly in $21 \%$ of trials. As a comparison, in the control condition, they only reported the second character correctly in $22 \%$ of trials, and only reported the third character correctly in $8 \%$ of trials. These results suggested that Chinese readers have difficulty simultaneously reporting both of the repeated characters in the repeated condition.

\section{Experiment 2A}

\section{Method}

Participants. Thirty-five native Chinese speakers from universities near the 
Institute of Psychology, Chinese Academy of Sciences (age: $M=21.44, S D=2.56 ; 18$ males) participated in Experiment 2A and received a small amount of monetary compensation. All of them had either normal or corrected to normal vision, and were naïve regarding the purpose of the experiment. None of them participated in Experiment 1.

Materials. The same sixty pairs of four-character strings ABCD used in Experiment 1 were used in Experiment 2A. Each pair of four-character strings was embedded into a same sentence frame and the critical four-character strings were never at the beginning or end of a sentence (see Figure 3 for an example). The naturalness of all sentences was assessed by ten volunteers on a seven-point scale $(1=$ not natural at all, 7 = very natural) to ensure that all sentences were easy to understand. There was no significant difference between the repeated condition $(M=5.47, S D=0.71)$ and the control condition $(M=5.50, S D=0.73 ; p>.1)$. The plausibility of all sentences was assessed by nine volunteers on a seven-point scale $(1=$ not plausible at all, $7=$ very plausible) to ensure that all sentences made sense. There was no significant difference between the repeated conditions $(M=5.53, S D=0.67)$ and the control condition $(M=$ $5.54, S D=0.62)$ with regard to plausibility $(p s>.78)$. The predictability of the target word was close to zero $(M=0.02, S D=0.07$ in the repeated condition, and $M=0.04$, $S D=0.08$ in the control condition) as assessed by nine additional participants who did not participate in the formal experiments. There was no significant difference in predictability between the two conditions $(p=.17)$. Each participant saw half of the 60 experimental sentences in the repeated condition and the other half in the control 
condition. Sixty experimental trials were presented in a random order following eight practice trials.

\section{Experiment 2A}

The repeated condition: 心理学上的行动动机是因为人们的需求而产生的。

(In psychology behavioral motivation is due to people's needs.)

The control condition: 心理学上的行动欲望是因为人们的需求而产生的。

(In psychology behavioral desire is due to people's needs.)

\section{Experiment 2B}

The repeated condition: 这辆公共汽车车门上贴满了某杂志周刊的广告。

(The bus door is covered with an advertisement for a magazine.)

The control condition: 这辆公共汽车后门上贴满了某杂志周刊的广告。

(The back door of the bus is covered with an advertisement for a magazine.)

Figure 3. Materials used in Experiments 2A and 2B. The target words are shown in bold for the purpose of illustration, and they were not shown in bold during the experiment.

Apparatus. The apparatus was identical to Experiment 1 except that each sentence was displayed on a single line in Song 20-point font in white (RGB: 255, 255, 255) on a black background (RGB: 0, 0, 0). Participants' eyes were positioned approximately $58 \mathrm{~cm}$ away from the computer monitor. At this viewing distance, each character subtended a visual angle of about $1^{\circ}$. Participants read sentences binocularly, but only the right eyes were monitored.

Procedure. The eye tracker was calibrated at the beginning of the experiment and was calibrated again as needed. A three-point calibration procedure was used. 
Participants were asked to read silently and to answer comprehension questions following one third of the sentences. The questions were used to ensure that participants read the sentences carefully and for comprehension. Each sentence appeared after participants fixated on a character-sized box at the location of the first character of each sentence. After reading a sentence or answering a comprehension question, the participants were asked to press a response button to start the next trial.

Analysis. The following measurements on the target words (region $\mathrm{AB}$ ) and the post-target (region CD) are reported: first fixation duration (the duration of the first first-pass fixation on the target word), gaze duration (the sum of all first-pass fixations on the target word before moving to another word), total viewing time (the sum of all fixations on the target word, including regressions), skipping probability (the probability that the target word was skipped on first-pass reading), probability of regression in and probability of regression out. During reading, first fixation duration, gaze duration, skipping probability are usually considered as reflecting early stage of processing such as lexical access, while total time, probability of regression in and probability of regression out reflects late stages for processing such as semantic integration or error correction (Radach \& Kennedy, 2013; Rayner, 1998; 2009).

We analyzed the above eye movement measurements for target words and posttarget words using generalized linear mixed models (Baayen, Davidson, \& Bates, 2008) in the $\mathrm{R}$ statistical software ( $\mathrm{R}$ Development Core Team, 2018). We report the regression coefficients $(b)$, standard errors, and test statistics ( $t$-values for the linear mixed models or $z$-values for generalized linear mixed models with a logit link 
function). Even though the Wald statistics are interpretable directly, we also estimated p-values using the lmerTest package. The analysis included condition (repeated vs. control) as a fixed effect factor. We fitted a maximum model including random slopes for condition (see Barr, Levy, Scheepers, \& Tily, 2013) and random intercepts for participants and items, but a likelihood-ratio test showed that this maximum model did not perform significantly better than the restricted model with only random intercepts for participants and items. Because of this, we only report the results of the restricted model. As fixation times often show a deviation from normality (long right tail), all fixation time values were log-transformed in order to correct for this.

\section{Results}

Accuracy on the comprehension questions was high (above 95\%), indicating that the participants understood the sentences well. Trials were removed if there was a blink inside the critical four-character region. In all, 116 trials $(5.5 \%$ of all trials) in the repeated condition and 121 trials (5.8\% of all trials) in the control condition were removed. Fixations with durations longer than $800 \mathrm{~ms}$ or shorter than $80 \mathrm{~ms}$ were also excluded from the analysis (Angele et al., 2013), resulted in 479 fixations being removed. Additionally, data points which were more than three standard deviations from the mean (calculated within participants and conditions) were removed as well ${ }^{1}$.

\footnotetext{
1 The two removal steps target different potential problems in the data that can lead to extraneous variability. The first step of the outlier removal based on the absolute limits (80 and $800 \mathrm{~ms}$ ) removes physiologically implausible measurements (very short and very long fixations). The second step, based on the $3 \mathrm{SD}$ criterion removes a small number of individual trials where the natural reading process was disrupted, e.g. because the participant was distracted.
} 
In this way, 453 first fixation durations, 453 gaze durations and 320 total times were removed from the analyses. We report eye movement measures in the two regions of interest (region $\mathrm{AB}$ and region $\mathrm{CD}$ ) separately.

Table 3

Eye movement measures in the $A B$ and $C D$ regions in Experiment $2 A$

\begin{tabular}{ccccc}
\hline & \multicolumn{2}{c}{ Region AB } & \multicolumn{2}{c}{ Region CD } \\
\cline { 2 - 5 } & Repeated & Control & Repeated & Control \\
\hline First fixation duration & $257(90)$ & $263(95)$ & $276(100)^{+}$ & $264(105)$ \\
Gaze duration & $319(185)$ & $323(181)$ & $338(209)^{* *}$ & $314(209)$ \\
Total time & $509(392)$ & $508(369)$ & $537(425)^{*}$ & $508(414)$ \\
Skipping probability & $.25(.44)$ & $.29(.46)$ & $.25(.45)$ & $.25(.44)$ \\
Regression out & $.37(.48)$ & $.40(.49)$ & $.20(.33)$ & $.20(.31)$ \\
Regression in & $.11(.32)$ & $.10(.29)$ & $.27(.49)$ & $.27(.50)$ \\
\hline
\end{tabular}

Note: 1) First-fixation duration, gaze duration, and total time were measured in milliseconds. 2) SDs are given in parentheses. 3) The following symbols indicate whether the value in the repeated condition was significantly different from that in the control condition: $+p<.1 . \quad * p<.05 . \quad * * p<.01$.

The eye movement measures are shown in Table 3. In the Region AB, none of the eye movement measures showed significant differences between the repeated condition and the control condition (all $t \mathrm{~s}<1$ ). However, the eye movement measures on the later region $\mathrm{CD}$ indicated a clear difference between the two conditions. Readers spent longer time on $\mathrm{CD}$ in the repeated condition than in the control condition both in terms 
of gaze duration $(b=-0.07, S E=0.02, t=-2.97, p=.003)$, and total time $(b=-0.05, S E$ $=0.03, t=-2.10, p=.036)$. Moreover, first fixation duration showed a trend in the same direction although the effect was only marginal $(b=-0.03, S E=0.02, t=-1.86, p=.063)$. Skipping probability, probability of regression out and probability of regression in were not significantly different in the repeated condition and the control condition $(z \mathrm{~s}<1.2)$.

In the present experiment, we found an inhibition effect in the later processing stage but no in the early processing stage. It was possible that the compound characters were repeated in the character level. But in the radical level, they were not repeated. It might be possible that the inhibition would occur at early stage and have strong effect if the repeated characters were repeated in both radical and character level. In Experiment 2B, we used simple characters, which were repeated in both radical and character level, to investigate how participants process repeated characters during reading.

\section{Experiment 2B}

\section{Method}

Participants. Thirty-eight native Chinese speakers from Shaanxi Normal University (age: $M=22, S D=1.5 ; 8$ males) participated in Experiment 2B, receiving a small payment as compensation for their participation. All of them had either normal or corrected to normal vision, and were naïve regarding the purpose of the experiment.

Materials. Sixty pairs of sentences containing critical four-character strings ABCD were used in Experiment 2B. Unlike in Experiment 2A, all repeated characters were simple characters with a single radical (e.g. 车, chē, means vehicle). Word 
frequencies of the word $\mathrm{CD}$ and character frequencies of characters $\mathrm{C}$ and $\mathrm{D}$ did not show significant differences between the repeated condition and the control condition $(t \mathrm{~s}<1)$. There was no significant difference in the number of strokes between the two conditions $(p>.05)$ (see Table 4). The four-character strings with the repeated and the control characters were embedded into the same sentence frame and the critical fourcharacter strings were never at the beginning or the end of a sentence (see Figure 3). The naturalness of all sentences was assessed by 20 volunteers on a seven-point scale to ensure that all sentences were easy to understand. The plausibility of all sentences was assessed by eight volunteers on a seven-point scale to ensure that all sentences made sense. The results showed no significant difference in naturalness and plausibility ratings between the repeated conditions $(M=6.14, S D=0.28$ for naturalness; $M=5.35$, $S D=0.72$ for plausibility $)$ and the control condition $(M=6.10, S D=0.27$ for naturalness; $M=5.42, S D=0.76$ for plausibility, $p \mathrm{~s}>.1)$. The predictability of the target word (CD) was zero, as assessed by 20 additional participants who did not participate in the formal experiments. In addition to the experimental sentences, we added 60 filler sentences. Each participant saw 30 sentences in the repeated condition, 30 in the control condition and 60 filler sentences. Sixty experimental trials were presented in a random order following six practice trials.

\section{Table 4}

Properties of materials used in Experiment $2 B$

\begin{tabular}{cccc}
\hline & First word & $(\mathrm{AB})$ & \multicolumn{2}{c}{ Second word (CD) } \\
Repeated & Control & Repeated & Control \\
\hline
\end{tabular}




$\begin{array}{ccccc}\begin{array}{c}\text { Word frequency } \\ \text { Character frequency of the first } \\ \text { character }\end{array} & 1990(2690) & 1990(2690) & 1745(1876) & 1938(1942) \\ \begin{array}{c}\text { Character frequency of the } \\ \text { second character }\end{array} & 1745(1786) & 1745(1786) & 1288(1266) & 1289(1266) \\ \begin{array}{c}\text { Stroke number of the first } \\ \text { character }\end{array} & 7.52(3.3) & 7.52(3.3) & 4.87(1.62) & 5.28(1.78) \\ \begin{array}{c}\text { Stroke number of the second } \\ \text { character }\end{array} & 4.87(1.62) & 4.87(1.62) & 7.15(2.91) & 7.15(2.91)\end{array}$

Note: 1) SDs are given in parentheses. 2) The units of word frequency and character frequency was times of occurrence per million. 3) In both the repeated and the control condition the first word $\mathrm{AB}$ are exactly the same (eg. 汽车 of both 汽车车门 in the repeated condition and 汽车后门 in the control condition). 4) The first character refers to $\mathrm{A}$ in the first word and $\mathrm{C}$ in the second word. The second character refers to $\mathrm{B}$ in the first word and D in the second word.

Apparatus. The stimuli were presented on a 24-inch LCD monitor (ASUS VG248QE) with a resolution of 1920 x 1080 pixels and a refresh rate of $144 \mathrm{~Hz}$. Each sentence was displayed in Song 24-point font in black (RGB: 0, 0, 0) on a grey background (RGB: 128, 128, 128). Participants' eyes were approximately $62 \mathrm{~cm}$ away from the computer monitor. At this viewing distance, each character subtended a visual angle of about $0.8^{\circ}$. We used an Eyelink 1000 plus (SR Research Ltd, Ontario, Canada) eye tracker with a sample rate of $1000 \mathrm{~Hz}$ to track participants' eye movements. A chin rest was used to minimize head movements. Participants read the sentences binocularly, but only the right eyes were monitored.

Procedure and Analysis. The procedure and analysis were identical to that in Experiment 2A.

\section{Results}

Accuracy on the comprehension questions was high (above $97 \%$ ), indicating that 
the participants understood the sentences well. Trials were removed if participants blinked inside the four-character critical region. Fixations with durations longer than $800 \mathrm{~ms}$ or shorter than $80 \mathrm{~ms}$ were also excluded from the analysis, as well as observations more than three standard deviations from the mean within participants and conditions. In all, 152 trials ( $6.7 \%$ of all trials) in the repeated condition and 139 trials (6.1\% of all trials) in the control condition were removed. Results are shown in Table 5.

Table 5

Eye Movement Measures in the Word $A B$ and $C D$ Region in Experiment $2 B$

\begin{tabular}{|c|c|c|c|c|}
\hline & \multicolumn{2}{|c|}{ Region $\mathrm{AB}$} & \multicolumn{2}{|c|}{ Region CD } \\
\hline & Repeated & Control & Repeated & Control \\
\hline First fixation duration & $254(50)$ & $253(46)$ & $260(44)$ & $257(52)$ \\
\hline Gaze duration & $275(185)$ & $278(57)$ & $294(65)^{*}$ & $281(70)$ \\
\hline Total time & $363(62)$ & $371(66)$ & $382(64)$ & $373(67)$ \\
\hline Skipping probability & $.34(.18)$ & $.33(.18)$ & $.27(.17)$ & $.28(.16)$ \\
\hline Regression out & $.11(.09)$ & $.11(.07)$ & $.18(.09)$ & $.20(.12)$ \\
\hline Regression in & $.43(.49)^{*}$ & $.47(.50)$ & $.30(.46)$ & $.33(.47)$ \\
\hline
\end{tabular}

Note: 1) First-fixation duration, gaze duration, and total time were measured in milliseconds. 2) SDs are given in parentheses. 3) The following symbol indicates whether the value in the repeated condition was significantly different from that in the control condition: $* p<.05$.

In region $\mathrm{AB}$, only the probability of the regression in showed significant 
difference $(b=-0.189, S E=0.096, z=-1.97, p=.049)$. None of the other eye movement measures showed any significant differences between the repeated condition and control condition (all $t \mathrm{~s}<1$ ). However, eye movement measures on the later region $\mathrm{CD}$ indicated a clear difference between the two conditions. Readers spent more time on $\mathrm{CD}$ in the repeated condition than in the control condition as measured in gaze duration $(b=0.018, S E=0.008, t=2.26, p=.024)$. Total time showed a similar, but nonsignificant trend $(b=0.016, S E=0.011, t=1.5, p=.120)$. There were no significant differences on first fixation duration between the two conditions, the skipping probability, probability of regression out and probability of regression in between the two conditions. Though the effect size was reduced in Experiments $2 \mathrm{~B}$ compared with Experiment 2A, the result showed a similar pattern.

\section{General Discussion}

The present research investigated how Chinese readers process repeated characters during natural reading. Results showed that processing repeated characters required extra effort for Chinese readers. In Experiment 1, the report accuracy of the repeated characters in a whole report task was significantly lower than that in the control condition. In Experiments $2 \mathrm{~A}$ and $2 \mathrm{~B}$, fixation durations on the words that contained the second repeated characters were longer than those in the control condition, no matter whether the characters were simple or complex. All of the experiments showed that the presentation of repeated characters inhibited word processing, which suggests that repeated characters cause processing difficulty. 
The two words that contained the repeated characters were not influenced by the repeated characters equally. In Experiment 1, participants reported the first repeated character more often than the second one; and in Experiments $2 \mathrm{~A}$ and $2 \mathrm{~B}$, none of the eye movement measures differed between the repeated character condition and the control condition on the first word that contained the repeated character. This suggests that the processing of the first word containing the repeated character is not affected, but the second word is affected. If words are processed in parallel, we would have expected that the repeated characters affect the processing of both words that are constituted by the repeated characters. However, the results of Experiments $2 \mathrm{~A}$ and $2 \mathrm{~B}$ showed that the reading times on the word constituted by the second repeated character was influenced by repeated characters, while the word on the left was not influenced.

These results can be explained by a serial model such as E-Z Reader (Reichle et al., 1998). According to serial models, the word on the left is processed first, and the first repeated character is assigned to that word. After the word on the left is processed, and when readers processed the second repeated character, they have difficulty in achieving token individuation for that character, and thus need some extra time to process the second word. As reviewed in the Introduction, participants had difficulty in separating the two different tokens of one type, and thus readers confused two identical characters as a single character (Kanwisher, 1987). Therefore, in Experiment 1, when participants saw the repeated characters for only $40 \mathrm{~ms}$, it was easy to view the two repeated characters as one singly character. That was why we observed the results that readers rarely report both of the repeated characters correctly. In Experiments $2 \mathrm{~A}$ and 
$2 \mathrm{~B}$, once a character is token individuated, a second token of the same type faces difficulty in being individuated, thus readers need more time to do so. This can explain the finding of longer fixation durations when Chinese readers read character strings with repeated characters in Experiments 2A and 2B.

The findings of the current study can also shed some light regarding the debate on whether repetition blindness occurs at the visual perceptual stage or memory/response stage (Crowder, 1968; Gilinsky, 1968; Kanwisher, 1987; Masson, 2004; Park \& Kanwisher, 1994; Potter, 1984; Rachel \& Sally, 2008; Whittlesea, Dorken \& Podrouzek, 1995). Some researchers assumes that repetition blindness happens at the visual perception stage (Kanwisher,1987; Park \& Kanwisher,1994; Potter, 1984), while other researchers claimed that repetition blindness occurs at a later stage, caused by failure of retrial or repose bias (Crowder, 1968; Masson, 2004; Rachel \& Sally, 2008; Whittlesea, Dorken, \& Podrouzek, 1995 ). However, in the natural reading task of Experiments $2 \mathrm{~A}$ and $2 \mathrm{~B}$, participants did not need either to remember or to report the repeated character yet still showed a repetition effect. Thus, the inhibition effect of our result is more likely to occur at the visual perception stage.

It should be note that although the results of the current study favor the view that words are processed serially, neither the serial models nor the parallel models that were proposed for reading alphabetic languages can easily be used in Chinese reading. In Chinese, there are no explicit markers (such as inter-word spaces) demarcating word boundaries. Thus, Chinese readers do not know where the word boundaries are before they process those characters. This poses significant difficulties for both serial models 
and parallel models. To address this problem, a model of word segmentation and word recognition was proposed for Chinese reading (Li et al., 2009). According to this model, readers process characters within the perceptual span in parallel (with the constrain of visual acuity as a function of eccentricity) (Li et al., 2009; Ma, Li, \& Rayner, 2014). All of the words constituted by these characters are activated and they compete for a single winner. When one word wins the competition, it is identified and is simultaneously segmented from the other text. Thus, the model assumes that word recognition and word segmentation is a unified process, without one happening earlier than the other. In some sense, the model is a serial model since only one word can win the competition at a time. However, different from traditional serial models, this model assumes that all of the characters in the perceptual span are processed in parallel and all of the words constituted by these characters are activated and compete with each other (See McClelland \& Elman (1986) and Shillcock (1990) for similar proposals that account for the word segmentation problem during spoken language processing).

Such model can also explain the inhibition effect observed in the present study. When a Chinese reader sees the character string 行动动机, and fails to token individuate the repeated characters, they are likely to perceive the two repeated characters as one. Thus, the central characters contribute to the recognition of 行动, while also contributing to the recognition of 动机. These activated words compete with each other for a single winner. When one of the words (行动 or 动机) wins the competition, the 动 character is assigned to that word since the reader is unaware of the characters being repeated. This then causes difficulty as the readers try to identify 
the other word, and, depending on the task, participants either fail to report one of the repeated characters (as in Experiment 1) or (as in Experiments 2A and 2B) they need some extra time to fix the error and re-process the words to ensure they perceive the repeated characters as two characters rather than just one.

Although the pattern of results was similar in our two experiments, there were some differences. In Experiment 1, both of the repeated characters showed inhibition effects while in Experiment 2 only the second repeated character showed the inhibition effect. This might be caused by the difference in setup and tasks. In Experiment 1, the stimuli were presented very briefly, and task was to report as many characters as possible. Readers might try their best to deploy their attention to all of the four characters so that they can recognize more characters. Therefore, the processing might be more parallel. In contrast, in Experiments $2 \mathrm{~A}$ and $2 \mathrm{~B}$, readers performed a natural reading task for comprehension, and they could spend as long as they wanted on each word. Since word order is important for comprehension, the processing might be more serial in this task. Thus, the repeated characters affect the word on the right much more than on the left.

Unlike our experiments, previous research on repeated words during reading showed a benefit attributed to parafoveal-on-foveal "leakage" in when processing of the first word was facilitated, when processing of the second word was facilitated (Angele et al., 2013; Inhoff et al., 2000; Raney \& Rayner, 1995). Why did we not observe facilitation effects? It is likely that repetition benefits apply at the word or passage level rather than the character level. In Inhoff et al.'s (2000) study, repeated words were presented in the same sentences as part of a legal (if slightly unusual) 
sentence structure (e.g. "Did you see the picture of her mother's mother at the meeting?"). Their results showed that the first fixation duration and gaze duration of the repeated words were shorter than those of unassociated words (e.g. "Did you see the picture of her mother's garden at the meeting?"), but nearly the same as those of associated words ("Did you see the picture of her mother's father at the meeting?"). In summary, the previous studies discussed used repetition manipulations at a different level compared to the present study. In our experiments, the repeated characters were directly adjacent, while in the previous studies, the repeated words were separated at least by a space and the genitive marker "s".

Angele et al. (2013) used the gaze-contingent boundary paradigm (Rayner, 1975) to investigate the influence a repetition preview to the right of the currently fixated word. They found a facilitation effect on fixation duration on the pre-boundary word "news" both of the identical preview and of the orthographically related nonword preview, but not of the semantically related preview. Of course, Chinese characters are units at the morphological rather than the orthographical level, and each character comes with its own meaning, orthography, and phonology. The nonword, in contrast, only has a phonological representation but no meaning (apart from the similarity to "news" in the example). Most critically, unlike Angele et al.'s (2013) experiments, the present studies did not involve a gaze-contingent display change. Rather than being able to update the representation of the word containing the repetition (word CD) after a display change (for example, participants in Angele et al.'s study were able to update the representation from "news" to "this" after they had crossed the boundary), 
participants in our studies had to identify both words $A B$ and $C D$ despite the degree of overlap they contained. Visual crowding (Levi, 2008) is another possible explanation of the discrepancies between our results and Angele et al.'s. While the repeated words were separated by spaces in English, the were no spaces between repeated characters in Chinese. In such a situation, participants might be affected by visual crowding. If so, if a space or another character were to be added between the repeated characters, the inhibition may be reduced or even disappear. In future research, it may be interesting to investigate whether nonconsecutive repeated characters also cause inhibition.

Previous studies showed that readers sometimes make some mistakes on parsing during sentence comprehension (Frazier \& Fodor, 1978). When this happens, readers usually make more regressions to fix the problems (Frazier \& Rayner, 1982). In the current study, although the repeated characters caused longer fixation durations on the word that included the second repeated character, it did not cause more regressions. This might be caused by the fact that readers might be able to identify the failure in token differentiation caused by repeated characters early enough so that they can fix the problem during first-pass reading, and thus no regression is needed to address this problem.

It should be noted that although the three experiments clearly showed that character repetition inhibits word processing, it obviously does not affect reading performance in Chinese overall (Liversedge, Drieghe, Li, Yan, Bai, \& Hyönä, 2016). This most likely because instances of repeated characters are not very frequent - though, as the naturalness ratings for Experiments $2 \mathrm{~A}$ and $2 \mathrm{~B}$ show, they are perfectly acceptable, 
unlike in English.

In summary, the current study demonstrates there is a processing cost when two identical characters occur in a row. This cost becomes apparent on the second character, both in a character identification task and normal reading task. These results generally favor the view that words are processed serially in natural reading.

\section{Reference}

Angele, B., Tran, R., \& Rayner, K. (2013). Parafoveal-foveal overlap can facilitate ongoing word identification during reading: Evidence from eye movements. Journal of Experimental Psychology: Human Perception \& Performance, 39(2), 526-538. doi:10.1037/a0029492.

Baayen, H. R., Davidson, D. J., \& Bates, D. M. (2008). Mixed-effects modeling with crossed random effects for subjects and items. Journal of Memory and Language, 59, 390-412.

Barr, D. J., Levy, R. , Scheepers, C., \& Tily, H. J. (2013). Random effects structure for confirmatory hypothesis testing: keep it maximal. Journal of Memory and Language, 68(3), 255-278.

Bjork, E. L., \& Murray, J. T. (1977). On the Nature of Input Channels in Visual Processing. Psychological Review,84(5),472-484. doi: 10.1037/0033295X.84.5.472

Crowder, R. G. (1968). Intraserial repetition effects in immediate memory. Journal of Verbal Learning \& Verbal Behavior, 7, 446-451. 
Egeth, H. E., \& Santee, J. L. (1981). Conceptual and perceptual components of interletter inhibition. Journal of Experimental Psychology: Human Perception and Performance, 7(3), 506-517. doi: 10.1037/0096-1523.7.3.506

Engbert, R., Nuthmann, A. , Richter, E. M. , \& Kliegl, R. (2005). SWIFT: a dynamical model of saccade generation during reading. Psychological Review, 112(4), $777-813$.

Frick, R. W. (1987). The homogeneity effect in counting. Perception \& Psychophysics, 41(1), 8-16. doi: 10.3758/BF03208207

Frazier, L., \& Fodor, J.D. (1978). The sausage machine: A new two-stage parsing model. Cognition, 6, 1-34.

Frazier, L., \& Rayner, K. (1982). Making and correcting errors during sentence comprehension: Eye movements in the analysis of structurally ambiguous sentences. Cognitive Psychology, 14, 178-210.

Gilinsky, A.S. (1968). Orientation-specific effects of patterns of adaptation light on visual acuity. Journal of the Optical Society of America, 58, 13-18.

Inhoff, A. W., Radach, R., Starr, M., \& Greenberg, S. (2000). Allocation of visuo-spatial attention and saccade programming during reading. In Kennedy, A., Radach, R., Heller, D.,\& Pynte, J. (Eds.), Reading as a Perceptual Process (pp. 221-246). Oxford: Elsevier Science Ltd. doi:10.1016/b978-008043642-5/50012-7

Inhoff, A. W., \& Liu, W. (1998). The Perceptual span and oculomotor activity during the reading of Chinese sentences. Journal of Experimental Psychology: Human Perception and Performance, 24(1), 20-34. 
Kanwisher,N.(1987). Repetition blindness: Type recognition without token individuation. Cognition, 27(2), 117-143.

Kanwisher, N. (1991). Repetition blindness and illusory conjunctions: Errors in binding visual types with visual tokens. Journal of Experimental Psychology: Human Perception and Performance, 17, 404-421.

Kanwisher, N. \& Potter, M. (1990). Repetition blindness: Levels of processing. Journal of Experimental Psychology: Human Perception and Performance, 16, 30-47.

Levi D. M. (2008). Crowding--an essential bottleneck for object recognition: a minireview. Vision Research, 48(5), 635-654. doi:10.1016/j.visres.2007.12.009

Li, X., Gu, J., Liu, P., \& Rayner, K. (2013). The advantage of word-based processing in Chinese reading: Evidence from eye movements. Journal of Experimental Psychology: Learning Memory \& Cognition, 39(3), 879. doi:10.1037/a0030337

Li, X., Rayner, K., \& Cave, K. R. (2009). On the segmentation of Chinese words during reading. Cognitive Psychology, 58(4), 525-552.

Liversedge, S. P., Drieghe, D., Li, X., Yan, G. L., Bai, X. J., \& Hyönä, J. (2016). Universality in eye movements and reading: A trilingual investigation. Cognition, 147, 1-20. doi:10.1016/j.cognition.2015.10.013

Ma, G., Li, X., \& Rayner, K. (2014). Word segmentation of overlapping ambiguous strings during Chinese reading. Journal of Experimental Psychology: Human Perception \& Performan, 40(3), 1046-1059.

Ma, G., Pollatsek, A., Li, Y., \& Li, X. (2017). Chinese readers can perceive a word even when it's composed of noncontiguous characters. Journal of Experimental 
Psychology: Learning, Memory, and Cognition, 43(1), 158-166.

McClelland, J. L., \& Elman, J. L. (1986). The TRACE model of speech perception. Cognitive Psychology, 18(1), 1-86.

Masson, M. E. J. (2004). When words collide: Facilitation and interference in the report of repeated words from rapidly presented lists. Journal of Experimental Psychology: Learning, Memory, and Cognition, 30, 1279-1289.

Mozer, M. C. (1989). Types and tokens in visual letter perception. Journal of Experimental Psychology: Human Perception and Performance, 15(2), 287303. doi: 10.1037/0096-1523.15.2.287

Park, J., \& Kanwisher, N. (1994). Determinants of repetition blindness. Journal of Experimental Psychology: Human Perception \& Performance, 20(3), 500-519.

Potter, M.C. (1984). Rapid serial visual presentation (RSVP): A method for studying language processing. In D.E. Kieras \& M.A. Just (Eds.), New methods in reading comprehension research. $\mathrm{NJ}$ : Hillsdale.

Rachel, B. , \& Sally, A . (2008). Repetition blindness in sentence contexts: Not just an attribution? Memery \& Cognition, 36(2), 295-313.

Rayner, K. (1975). The perceptual span and peripheral cues in reading. Cognitive Psychology, 7(1), 65-81.

Rayner, K. (1998). Eye movements in reading and information processing: 20 years of research. Psychological Bulletin, 124(3), 372-422.

Rayner, K. (2009). Eye movements and attention in reading, scene perception, and visual search. The Quarterly Journal of Experimental Psychology, 62(8), 1457- 
1506. doi: $10.1080 / 17470210902816461$

Reichle, E. D., Pollatsek, A., Fisher, D. L., \& Rayner, K. (1998). Toward a model of eye movement control in reading. Psychological Review, 105(1), 125-157. doi:10.1037/0033-295x.105.1.125

Reichle, E. D., Rayner, K., \& Pollatsek, A. (2003). The E-Z reader model of eyemovement control in reading: Comparisons to other models. Behavioral \& Brain Sciences, 26(4), 477-526.

R Development Core Team (2018). R: A language and environment for statistical computing. Vienna, Austria. $\mathrm{R}$ Foundation for Statistical Computing. https://www.R-project.org/.

Santee, J. L., \& Egeth, H. E. (1980). Interference in letter identification: A test of feature-specific inhibition. Perception \& Psychophysics, 27(4), 321-330.

Schotter, E. R., Angele, B., \& Rayner, K. (2012). Parafoveal processing in reading. Attention Perception \& Psychophysics, 74(1), 5-35. doi: 10.3758/s13414-0110219-2

Shillcock, R. (1990). Lexical hypotheses in continuous speech. In G. T. M. Artmann (Ed.), Cognitive models of speech processing. Psycholinguistic and Computational Perspectives (pp. 24-49). Cambridge, MA: MIT Press.

Whittlesea, B. W. A., Dorken, M. D., \& Podrouzek, K. W. (1995). Repeated events in rapid lists: Part 1. Encoding and representation. Journal of Experimental Psychology Learning Memory \& Cognition, 21(6), 1670-1688.

Zhan, W., Guo, R., \& Chen, Y.(2003). The CCL corpus of Chinese texts, Retrieved from 
http://ccl.pku.edu.cn:8080/ccl_corpus 